\title{
Revenge and forgiveness after victimization: psychometric evaluation of a Dutch version of the TRIM intended for victims and offenders
}

\author{
Coby Gerlsma ${ }^{1}$ (D) Valerie Lugtmeyer ${ }^{2}$ - Mariëtte Van Denderen ${ }^{3}$ • Jos De Keijser ${ }^{1,2}$
}

Accepted: 11 December 2020 / Published online: 22 December 2020

(C) The Author(s) 2020

\begin{abstract}
The Transgression Related Interpersonal Motivations (TRIM) scale measures revenge, avoidance, and benevolence in response to social transgressions that, typically, comprise acts of indirect aggression. We tailored the TRIM for use in forensic psychiatric and victimological settings by slightly altering the instruction to include transgressions that comprise direct as well as indirect aggression. In this study, we examined the factor structure and psychometric qualities of this adapted Dutch version of the TRIM. Data was collected in adolescents from three different educational levels $(N=455)$ and in (ex)detainees $(N=65)$. Three unambiguous and internally consistent factors corroborated a priori conceptualizations. Associations with social desirability, dispositional anger, dispositional vengeance, accomplished revenge, and accomplished forgiveness supported construct validity. Mean scores from (ex)detainees did not differ from the student participants, although the former reported more incidents of physical and sexual violence. Hence, the TRIM appears useful as an aid in risk assessment of known offenders, threat assessment of as yet unknown offenders, and efforts to support victims of violence.
\end{abstract}

Keywords Aggression · Victimization · Revenge $\cdot$ Assessment

Being harmed by another person generally elicits strong emotions about the perpetrator(s) (Beck, 1999, 2002; Anderson \& Bushman, 2002). Among other coping efforts, the experience may call for revenge (Worthington \& Wade, 1999), i.e. 'an aggressive, often violent, response to intentional harm that has been inflicted on the avengers and their families' (Stuckless, 1996, p. 21). Revenge is by definition a form of aggression. In 'revenge served cold' the appraisal of being harmed is the starting point of intense and persistent rumination about retaliatory action; in 'hot-blooded revenge' the score is evened in conclusion of the harming incident (McCullough, 2008). Hence, revenge comes in the guise of 'cold' (instrumental, proactive, predatory) as well as 'hot' (affective, reactive, retaliatory) variants of aggression.

Coby Gerlsma

j.gerlsma@rug.nl

1 Department of Psychology, University of Groningen, Grote Kruisstraat 2/1, 9712 TS, Groningen, The Netherlands

2 GGZ Friesland Polikliniek, Leeuwarden, The Netherlands

3 FPC Dr S. van Mesdag, Groningen, The Netherlands
The ultimate goal of a vengeful act is to restore equity: One has been made to suffer and demands retribution (Frijda, 1994; Baumeister, 1996). Whether and how equity is to be restored depends on considerations regarding attributions of blame (the extent to which the 'harm doer' is held responsible for the suffering), proportionality (the extent to which the magnitude of revenge equals the magnitude of the original harm), and morality and justice (the extent to which revenge is perceived as legitimate according to certain moral criteria) (Barnoux \& Gannon, 2013; Baumeister, 1996; Stillwell, Baumeister \& DelPriore, 2008).

Several formulations on violence picture revenge as a primary motive for violent offending in general (Gannon et al., 2007; Denson, 2013), for firesetting (Barnoux \& Gannon, 2013), sexual violence (Barnett, 2011), massmurder (Scheff, 2011), and (suicide) terrorism (Lankford \& Hakim, 2011). In a review of empirical findings by McCullough, Kurzban, and Tabak (2013), revenge was put forward as a causal factor in $10 \%$ to $20 \%$ of the homicides worldwide, $61 \%$ of school shootings, $27 \%$ of bombings, and as an inspiring factor for recruitment in terrorist organizations.

While victims of violence or injustice may strive to restore equity (Frijda, 1994; Baumeister, 1996), and generally expect to experience relief and closure after a successful act of 
revenge (Carlsmith, Wilson \& Gilbert, 2008), empirical studies have primarily reported detrimental effects (e.g., Schumann \& Ross, 2010). Following up on the studies by Bushman and colleagues $(2001,2002)$, who showed that venting anger did not bring relief but more anger instead, Carlsmith et al. (2008) demonstrated how taking revenge increased rather than decreased angry rumination and aggression. Moreover, revenge appeared associated with complicated grief (Bloom, 2001; Van Denderen et al., 2014), symptoms of post-traumatic stress disorder (PTSD) (Kunst, 2011; Orth, Montada, \& Maercker, 2006; Van Denderen et al., 2014), and cardiovascular problems (Miller, Smith, Turner, Guijarro, \& Hallet, 1996; Witvliet, Ludwig, \& Van der Laan, 2001). It seems that both harboring grudges as well as releasing them by actually taking revenge appears harmful (Denson, 2013; see however Strelan, DiFiore, \& Van Prooijen, 2017).

To signal revenge motivation and possibly avoid or prevent actual vengeful behaviour, a self-report instrument for the standardized assessment of revenge motivation might be helpful in forensic psychiatric as well as victimological research and practice. A self-report on revenge can contribute to risk assessment and management in forensic settings, for instance as a supplement to structured risk assessment by clinical forensic experts (e.g., Karsten et al., 2019). Furthermore, it may be an aid in threat analysis (Meloy et al., 2012), for instance in the context of workplace violence (e.g. Kausch \& Resnick, 2001; Wang et al., 2018), terrorism (e.g., Lotto, 2017) or school violence (Villaruel \& Dunbar, 2006). Furthermore, from a victimological stance, screening can be helpful in signaling whether victims of criminal offenses might need support or counseling. Within a judicial context, an index of a victim's revenge motivation towards the perpetrator might assist victim advocates in their task to inform and support victims during the juridical proceedings, whereas it might also contribute to discussions, decisions, and research in the context of Restorative Justice interventions (Choi, Bazemoor \& Gilbert, 2012; Sherman \& Strang, 2010; Worthington et al., 2011).

The Transgression Related Interpersonal Motivation scale (TRIM; McCullough, Rachal, Sandage, Worthington, Brown \& High, 1998; McCullough, Root \& Cohen, 2006) is a widely used and well-researched self-report measure of revenge and alternative ways of coping with victimization. McCullough and colleagues summarized coping responses to social transgressions in three dimensions of interpersonal motivation, i.e. revenge, benevolence, and avoidance. Together, these dimensions provide an index of forgiveness: High benevolence and low revenge and avoidance motivation are conceptualized to indicate forgiveness, and vice versa, low benevolence together with high revenge and avoidance are presumed to index an unforgiving stance toward the perpetrator. Factor analysis of the TRIM corroborated this a priori conceptualization, with a bipolar factor reflecting benevolent approach versus avoidance of the perpetrator, and a second, unipolar, factor reflecting revenge (McCullough et al., 2006; though see Forster et al., 2019, for an alternative interpretation of the dimensional structure that might underlie the forgivenessconcept that is assessed with the TRIM).

The TRIM subscales showed excellent psychometric qualities in a variety of (mainly student) samples, with internal consistency coefficients well above the recommended Cronbach's alpha $>.70$ criterion (Nunnally, 1978), and it has an extensive nomological network (e.g., McCullough, Kurzban, \& Tabak, 2013; Forster et al., 2019). Having been investigated in primarily social psychological experiments, the TRIM showed a theoretically meaningful pattern of associations with a variety of variables such as relationship satisfaction, relationship closeness, anger, rumination, apologies and other reconciliatory behaviour (McCullough et al., 1998, 2014). In a general population sample, Ghaemmaghami et al. (2011) showed that respondents' age and gender did seem to affect TRIM scores.

In view of the merits briefly summarized above, the TRIM seems a suitable instrument for the assessment of revenge (and alternative) motivation in both victims and perpetrators of violence and aggression. McCullough et al.'s formulations and findings place revenge motivation in a theoretical framework that could be a valuable guide for decisions in the context of risk and threat assessment, and in the context of support for victims of violence. Moreover, studying revenge motivated aggression conjointly with its functional opposite, forgiveness, may contribute to theories of aggression (Denson, 2013) and justice restoration (Strelan et al., 2017).

In order to use the TRIM in forensic psychiatric and victimological research and practice, the scale's instruction seems to require a slight adaptation. Originally (McCullough et al., 2006), the questionnaire was designed to measure interpersonal motivation in response to a social transgression in close relationships (McCullough et al., 1998, 2006). Recently, a TRIM version for Non-Close Others, the TRIMNCO, was also introduced (Forster et al., 2019). Both TRIMversions start with an incident registration: Respondents are requested to recall a social transgression, i.e., an incident in which one has been hurt by another person, that has occurred during the past week(s) or month, and to briefly describe that particular incident. Subsequently, respondents answer 18 selfreport questionnaire items about their revenge, avoidance, and benevolence motivation towards the transgressor of that incident. Typically, with this instruction respondents report incidents that involve social harms, such as insults, neglect, rejection, infidelity, betrayals of confidence, that do not involve direct aggression or violence (see for instance McCullough et al., 1998, 2006, 2014). To tailor the TRIM for use in forensic psychiatric and victimological settings, that is, with victims and perpetrators of criminal violence, the instrument would need to be able to invite valid responses about a wider range of 
transgressive incidents, that is, incidents involving both direct (and possibly penal) and indirect types of aggression. To this aim we therefore slightly adapted the instruction and asked respondents to recall an incident in which another person inflicted some kind of injustice or violence, that has occurred during one's lifetime, and to briefly describe that particular incident. Respondents answer the TRIM-items with this incident and transgressor in mind.

\section{Objectives of the Current Study}

The aims of the present study were (1) to translate the 18 TRIM-items into Dutch, (2) to adapt the scale's incident registration to elicit transgressions that involve both indirect and direct aggression, and (3) to evaluate its psychometric qualities and usefulness in relevant populations in The Netherlands.

As to the first aim, it should be noted that an earlier and shorter version of the TRIM (TRIM-12; McCullough et al., 1998) was translated into Dutch by Karremans and Van Lange (2004); however, this Dutch form did not include the Benevolence subscale, and its factor structure and psychometric qualities were not formally evaluated. We translated the current TRIM (TRIM-18, McCullough et al., 2006) with the consent of McCullough and Karremans (personal communication).

As to the second and third aim it is important to note that we altered the original TRIM's incident registration, examined to what extent the instrument actually does sample a wide variety of transgressions, including direct, physical, and sexual violence (see also Gerlsma, \& Lugtmeyer, 2018), and than evaluated the scale's factor structure and psychometric qualities. The rationale for this seemingly extensive evaluation of an already well-established scale is that we cannot presume, but have to empirically demonstrate, to what extent our version, tailored for use in forensic psychiatric and victimological settings, can be considered an analoque to the original TRIM (see also Briggs \& Cheek, 1986): It could make quite a difference whether one reports vengeful or avoidant motivation in response to being beaten up in a robbery or raped by one's neighbour, as compared to being insulted by a colleague or betrayed by one's girlfriend (Carmody \& Gordon, 2011; Gerlsma \& Lugtmeyer, 2018; McCullough, 2008; Rapske, Boon, Alibhai \& Kheong, 2010; Worthington \& Wade, 1999).

The considerations raised above led us to sample our data in sentenced offenders as well as in adolescents from the general community. There is, generally, a high rate of victimization among individuals who are sentenced for violent offences (e.g., Dutton \& Hart, 1992; Jennings, Piquero, \& Reingle, 2012; Mulford et al., 2018; Widom, 1989). Furthermore, the risk of becoming the victim or perpetrator of injustice or aggression appears to peak in adolescence (Cops \& Pleysier,
2014). Victimization in adolescence may then set the stage for a host of adverse developmental consequences (e.g., DeCamp, Zaykowski, \& Lunn, 2018; Turner, Shattuck, Finkelhor, \& Hamby, 2015; Turner, Shattuck, Hamby, \& Finkelhor, 2013), including the risk of escalating cycles of violence and victimization (e.g., Dodge, Bates, \& Pettit, 1990; Leary, Kowalski, Smith, \& Phillips, 2003; Stillwell, Baumeister, \& Del Priore, 2008; Widom, 1989). Both sentenced offenders and adolescents from the general community are therefore among the most relevant populations for our aims.

We expected this version of the TRIM-18 to show an interpretable factor structure, sufficient internal consistency of the subscales (Cronbach's alpha's >.70, cf. Nunnally, 1978), and a sensical pattern of correlations with related constructs, such as dispositional hostility and vengeance, accomplished forgiveness and vengeance, and social desirability response bias (i.e., the tendency to give overly positive self-descriptions). While any significant association of the TRIM with social desirability might be considered to contribute to measurement bias, the TRIM's relationship with dispositional vengeance and hostility, as well as accomplished forgiveness, would reflect meaningful relationships within the nomological forgiveness network (e.g., Forster et al., 2019; McCullough et al., 2006). With regard to this construct validational pattern, we expect that unforgiving motivations (i.e. high revenge and avoidance, and low benevolence) relate negatively with accomplished forgiveness and with social desirability response bias, whereas positive associations with accomplished revenge, dispositional anger and dispositional vengeance are expected (e.g., McCullough et al., 2006). We expect stable findings across gender and educational level, and between adolescents from the general community and individuals who have been sentenced for committing a violent offense. Stability of findings will bolster the generalizability and construct validity of this TRIM.

\section{Method}

\section{Participants and Procedure}

Data was collected in three educational settings, and two forensic settings.

Educational Settings The dataset collected in the educational settings (also included in Gerlsma \& Lugtmeyer, 2018) was provided by students from three different educational levels that together provide a fair representation of the educational range offered in our country. Participants were 188 secondary school students (106 
female, 75 male, 7 missing; mean age $=17.2$ years, $S D=1.5)$, 163 students in secondary vocational education (68 female, 94 male, 1 missing; mean age = 18.1 years, $S D=1.9$ ), and 104 undergraduate psychology students (80 female, 24 male; mean age $=19.4$ years, $S D=1.5)$. The undergraduate psychology students received credits for a course and the students in secondary vocational education and secondary school received a small treat for their enrollment.

The data was collected by means of a questionnaire booklet containing a few demographic questions, and the self-report questionnaires pertinent to our research questions (see below); the booklet finished with a mood repair (sorting comic strips) and thanks. The undergraduate psychology students read and signed an informed consent form and filled in the booklet digitally and on-line; the other participants received the informed consent and booklet on paper during school hours, and filled in the questionnaires in the presence of a research assistant.

Forensic Settings A total of 65 detainees participated, i.e. 30 male forensic psychiatric patients who had been sentenced with a treatment order, and 35 (ex)detainees (32 male). Mean age of the participants was 36.6 years $(\mathrm{SD}=10.5$, range from 19 to 62 ).

The 30 forensic psychiatric patients were treated in the 'Forensic Psychiatric Centre $N N$ '. To maximize response rate, we did not ask any questions about their criminal and psychiatric history. In general, a treatment order in our country involves offenses with a sentence of at least 4 years, such as (sexual) assault, rape, murder, (serial) fire setting. The data was collected by a member of the 'Forensic Psychiatric Center $N N$ ' research team and the third author of this paper. In a 2 month period, they visited all units to invite patients to participate and provided (and if necessary clarified) the informed consent and questionnaires; participants completed these in their own or in the communal room. These participants received 2.50 Euros for their cooperation.

The 35 (ex)detainees (had) served sentences from 0.1 to 11 years, with a mean of 2.6 years $(\mathrm{SD}=2.7)$. Their sentences involved assault (43\%), theft (40\%), drugs dealing $(37 \%)$, attempted murder $(34 \%)$, threats $(20 \%)$, robbery $(11.4 \%)$, fire setting $(3 \%)$, and murder $(3 \%) ; 68 \%$ were sentenced for multiple offences. At the time of the data collection, 13 of them were on conditional leave and participated in a training program for social reintegration and rehabilitation ('Rehabilitation program $N N$ '); the other 22 were ex-detainees who participated as hands-on experts in an educational program (organized by 'Educational program $N N^{\prime}$ ). The data was collected in a 2 month period by a research assistant of our Psychology Department, who visited the training centers and asked the (ex)detainees for their participation, answered questions and provided them with informed consent and questionnaires. It should be noted that in both forensic populations the response rate was very low (approximately 10\%).

\section{Measures}

\section{Revenge, Avoidance, and Benevolence Motivations}

The Transgression Related Interpersonal Motivation scale (TRIM; McCullough et al., 2006) measures revenge, avoidance, and benevolence in response to social transgressions. A combined score of the three subscales is an index of forgiveness (e.g., McCullough, 2008; McCullough et al., 2006). The TRIM was translated into Dutch by the first two authors, and translated back to English by a native speaker (cf. De Figueiredo \& Lemkau, 1980). Differences in wording and meaning that transpired were discussed, resulting in a consensus version (available upon request to the first author). The translated questionnaire starts with an incident registration, in which respondents answer the open ended question: "Many people experience injustice or violence at some time in their life. Please think of the person who has hurt you in this way. What kind(s) of injustice or violence did he/she do to you?" Subsequently, respondents are asked to keep the reported incident in mind while answering 18 items about their motivations towards the perpetrator, .i.e. Revenge ( 5 items, e.g., "I'm going to get even"), Avoidance (7 items, e.g., "I am trying to keep as much distance between us as possible"), and Benevolence (6 items, e.g., "Despite what he/she did, I want us to have a positive relation again"). All items are rated on a 7-point Likert-type scale, anchored $1=$ 'strongly disagree' to 7 = 'strongly agree'. Internal consistency coefficients will be reported in the Results section, since the composition of scales is contingent upon the factor structure found in our data analyses.

Accomplished Revenge and Forgiveness Two items were added to the Dutch TRIM as single item measures of accomplished Forgiveness ("I have forgiven him/her", Subkoviak et al., 1995) and accomplished Revenge ("I have taken my revenge on him/her"). These items were translated into Dutch, and had the same 7-point response format as was described above for the TRIM-items.

Dispositional Vengeance The Vengeance Scale (VS; Stuckless \& Goranson, 1992; Dutch version described in van Denderen et al., 2014) was used to assess individual differences in the attitude toward revenge. It consists of 20 items (e.g., "It is important for me to get back at people who have hurt me") that respondents answer on a 7-point Likert scale anchored (1) 'Disagree strongly' to (7) 'Agree strongly'. Internal consistency in this study was good $(\alpha>.80)$. 
Dispositional Anger We used the trait version of the Spielberger State-Trait Anger Scale (SSTAS; Spielberger, 1980; Dutch version by Van der Ploeg, Defares, \& Spielberger, 1982) to assess dispositional anger. The scale consists of 10 short self report items (e.g., "When I get frustrated, I feel like hitting someone"), to be answered on a 4point Likert scale anchored (1) 'hardly ever 'to (4) 'nearly always'. Internal consistency in this study was adequate $(\alpha$ $>.70)$.

Social Desirability The shortened Marlowe Crowne Social Desirability Scale (MCSDS; Crowne \& Marlowe, 1960; Dutch version by Nederhof, 1985) was used to assess response bias due to favorable self-presentation. The scale consists of 10 self-report items (e.g., "I have never intensely disliked anyone"), with the response format True/Untrue. Internal consistency in this study was adequate $(\alpha>$.70).

\section{Results}

\section{Description of Reported Incidents}

The verbatim descriptions of experiences with injustice or violence were categorized in four types of incidents, i.e. 'physical violence' (all kinds of (non-sexual) assault resulting in physical harm), 'sexual violence' (all kinds of sexual assault and maltreatment), direct, and indirect aggression. For the operationalization of the latter two general types of aggression we used the defining criteria described by Card, Stucky, Sawalari and Little (2008), with 'direct aggression' for 'physical reacts such as hitting, pushing, and tripping as well as overt verbal attacks such as name calling, taunting, and threatening' (p. 1186), and 'indirect aggression' for 'hurtful manipulation of relationships (e.g., sabotaging the target's friendships or romantic relationships) and damaging the target's social position (e.g., spreading gossip, excluding from activities) often through indirect or covert means' (p. 1186). All categories were coded as dichotomous dummy variables with value 1 if the respondents reported an incident that fitted the category, and value 0 if the incident did not fit the category; it should be noted that the categories were non-exclusive. Codes were based on the consensus of the first two authors. Table 1 provides a summary of descriptive figures.

In the three student groups, 24 participants (i.e. $5.3 \%$ of the total $N=455$ group) explicitly stated they had never been victimized in any way; these respondents were excluded from the analyses. Seventy-six participants (i.e. 16.7\%) refrained from answering the incident question, whereas they did answer the revenge, avoidance, and benevolence items; these respondents were included in the analyses and fell in the category 'Declined to answer'. The remaining respondents reported between 1 and 9 incidents, with mean 1.72 (SD 1.53).
Table 1 Categories of experiences with injustice and violence reported by students and (ex)detainees

\begin{tabular}{|c|c|c|c|c|}
\hline \multirow[b]{2}{*}{ TRIM ${ }^{\mathrm{a}}$ responses: } & \multicolumn{2}{|c|}{ Students N $=455$} & \multicolumn{2}{|c|}{ (ex)detainees $\mathrm{N}=65$} \\
\hline & $N$ & $\%^{\mathrm{b}}$ & $N$ & $\%^{\mathrm{b}}$ \\
\hline \multicolumn{5}{|c|}{ Categories of experiences: } \\
\hline Direct aggression & 171 & 37.6 & 32 & 49.2 \\
\hline Indirect aggression & 157 & 34.5 & 13 & 20.0 \\
\hline Physical violence & 69 & 15.2 & 26 & 40.0 \\
\hline Sexual violence & 14 & 3.1 & 10 & 15.4 \\
\hline 0 experiences & 24 & 5.3 & 2 & 3.1 \\
\hline Declined to answer & 76 & 16.7 & 12 & 18.5 \\
\hline
\end{tabular}

${ }^{a}$ TRIM: Transgression Related Interpersonal Motivations (McCullough et al., 2006)

${ }^{\mathrm{b}}$ Percentage of the total number of participants in this group (Note: because respondents could mention more than one experience, the percentages add up to $>100 \%$ )

The students reported experiences with direct aggression $(37.6 \%)$ as well as experiences with indirect aggression $(34.5 \%)$, whereas $18.5 \%$ reported physical or sexual violence. Within the student group, the students in the secondary vocational education level reported more incidents of direct aggression than the other two levels $\left(\chi^{2}=7.95 ; d f=2, p=.02\right)$. The women reported less physical violence than the men $\left(\chi^{2}=\right.$ 9.86, $d f=1, p=.002)$, and less incidents that involved direct aggression $\left(\chi^{2}=9.00, d f=1, p=.003\right)$.

In the forensic group, two participants could not recall any incident, whereas 12 participants declined to describe the recalled incident but did rate the TRIM-items. The remaining 51 (ex)detainees reported incidents in all four categories. Compared to the students, the (ex)detainees reported significantly $(p<.001)$ more incidents involving physical and sexual violence (55.4\% versus $18.3 \%$ ), while the proportion of incidents involving indirect aggression was smaller $(20 \%$ versus $34.5 \%$ ).

\section{Factor Analysis and Internal Consistency}

We examined the factor structure of the Dutch TRIM in the pooled student data, in order to have a sufficiently large and homogeneous dataset (according to practical guidelines sample size should preferably be $>300$ or reflect an item: respondent ratio of at least 1:10 (e.g., Bryant \& Yarnold, 1995; Tabachnik \& Fidell, 2007)) to increase the reliability and generalizability of findings. The internal consistency of the (sub)scales was investigated in all subgroups as well, including the (ex)detainees.

We performed an exploratory principal component analysis (PCA) with orthogonal (Varimax) rotation to estimate the factor structure of the TRIM without any pre-set limitations. 
This approach will indicate to what extent we can reliably use the subscales as indices of revenge, avoidance, and benevolence in The Netherlands in forensic and adolescent populations (Briggs \& Cheek, 1986), which is our main research interest. We chose an exploratory rather than a confirmatory approach in view of the higher order dimensional structure of the TRIM, which suggested multiple solutions (see McCullough et al., 2006; Forster et al., 2019), with the probability that secondary loadings would limit or complicate the data fit (Church \& Burke, 1994). Moreover, we felt that a replication of the three factor solution in new data in another culture and without any force or constraint would provide the strongest support for the scale (e.g., Briggs \& Cheek, 1986; Church \& Burke, 1994).

The data proved to be suitable for factor analysis with a Kaiser-Meyer-Olkin (KMO) coefficient of .89 (close to 'marvelous' according to Kaiser's (1974) criteria), and a significant Bartlett's test of sphericity $(p<.0001)$. The exploratory principal component analysis yielded three factors with an eigenvalue $>1$, which explained $59 \%$ of the variance. Factor loadings are presented in Table 2. The first factor (Eigenvalue $6.20 ; 34.5 \%$ variance) held 8 items with loadings $>.52$; all but one were Avoidance items. One item from the a priori Benevolence scale also 'strayed' in this factor, with a loading of -.52 , equal to its loading on the Benevolence factor. The second factor (Eigenvalue 2.90; 16.1\% variance) held five Revenge items; loadings were $>.68$. The third factor (Eigenvalue 1.52; $8.5 \%$ variance) held only Benevolence items; loadings $>$.46. Summarizing, factor analyses yielded a clear three-factor solution that fairly replicated the a priori scales, with only one item with substantial loadings on a secondary factor. Inter scale correlations showed a moderate association between Revenge and Benevolence $(r=-.51$, $p<.001$ ), and small to moderate associations between Revenge and Avoidance $(r=-.28, p<.001)$, and between Avoidance and Benevolence $(r=.39, p<.001)$.

As is summarized in Table 3, the reliability of the three TRIM subscales was good in all groups investigated, with

Table 2 Factor loadings of the $\mathrm{TRIM}^{\mathrm{a}}$ items in an exploratory factor analysis after orthogonal (Varimax) rotation in a three factor solution

\begin{tabular}{|c|c|c|c|c|}
\hline & TRIM-items & $\begin{array}{l}\text { Factor 1: } \\
\text { Avoidance }\end{array}$ & $\begin{array}{l}\text { Factor 2: } \\
\text { Revenge }\end{array}$ & $\begin{array}{l}\text { Factor 3: } \\
\text { Benevolence }\end{array}$ \\
\hline 1 & I'll make him/her pay & & .76 & \\
\hline 2 & I am trying to keep as much distance between us as possible & .77 & & \\
\hline 3 & Even though his/her actions hurt me, I have goodwill for him/her & & & .46 \\
\hline 4 & I wish that something bad would happen to him/her & & .75 & \\
\hline 5 & I am living as if he/she doesn't exist, isn't around & .72 & & \\
\hline 6 & I want us to bury the hatchet and move forward with our relationship & & & .70 \\
\hline 7 & I don't trust him/her & .63 & & \\
\hline 8 & Despite what he/she did, I want us to have a positive relationship again & -.52 & & .52 \\
\hline 9 & I want him/her to get what he/she deserves & & .68 & \\
\hline 10 & I am finding it hard to act warmly toward him/her & .59 & & \\
\hline 11 & I am avoiding him/her & .80 & & \\
\hline 12 & $\begin{array}{l}\text { Although he/she hurt me, I am putting the hurts aside so we could resume our } \\
\text { relationship }\end{array}$ & & & .73 \\
\hline 13 & I'm going to get even & & .75 & \\
\hline 14 & I forgive him/her for what he/she did to me & & & .67 \\
\hline 15 & I cut off the relationship with him/her & .79 & & \\
\hline 16 & I have released my anger so I can work on restoring our relationship to health & & & .69 \\
\hline 17 & I want to see him/her hurt and miserable & & .81 & \\
\hline 18 & I withdraw from $\mathrm{him} / \mathrm{her}$ & .79 & & \\
\hline
\end{tabular}

${ }^{\mathrm{a}}$ Notes: TRIM = Transgression Related Interpersonal Motivation scale (McCullough et al., 2006), ${ }^{\mathrm{b}}$ Only factor loadings $>.40$ are shown in the table 
Table 3 Internal consistency (Cronbach's $\alpha$ ) of the TRIMscales for revenge, avoidance, and benevolence motivation in students from three educational levels, male and female students, and ex-detainees

\begin{tabular}{lllllll}
\hline $\begin{array}{l}\text { Interpersonal } \\
\text { motivation }\end{array}$ & $\begin{array}{l}\text { Secondary } \\
\text { school } \\
\mathrm{N}=188^{\mathrm{a}}\end{array}$ & $\begin{array}{l}\text { Secondary } \\
\text { vocational school } \\
\mathrm{N}=163^{\mathrm{a}}\end{array}$ & $\begin{array}{l}\text { University } \\
\mathrm{N}=104\end{array}$ & $\begin{array}{l}\text { Male } \\
\text { students } \\
\mathrm{N}=193^{\mathrm{a}}\end{array}$ & $\begin{array}{l}\text { Female } \\
\text { students } \\
\mathrm{N}=254^{\mathrm{a}}\end{array}$ & $\begin{array}{l}\text { (Ex- } \\
\text { )detainees } \\
\mathrm{N}=65\end{array}$ \\
\hline Revenge & .86 & .82 & .82 & .82 & .85 & .87 \\
Avoidance & .89 & .83 & .91 & .84 & .90 & .85 \\
Benevolence & .73 & .78 & .79 & .82 & .73 & .85 \\
\hline
\end{tabular}

${ }^{a}$ Because data on gender was missing in one student from the secondary vocational school and seven secondary school students the numbers do not exactly add up
Conbach's $\alpha$ 's ranging from .73 to .91 . Nunnally (1978) recommended a minimum of $\alpha=.70$ for scales intended to measure psychological concepts in the context of research. Because Cronbach's $\alpha$ 's depend on the homogeneity as well as on the number of items within a scale, an $\alpha>.70$ can be interpreted as (very) good in a short scale (such as the TRIMsubscales) (Briggs \& Cheek, 1986).

\section{Construct Validity of the TRIM}

We examined the construct validity of the three TRIM subscales by means of their bivariate correlations with four conceptually relevant variables (i.e., Accomplished Forgiveness, Accomplished Revenge, Dispositional Vengeance, and Dispositional Anger), and one variable indicative of measurement bias (Social Desirability response bias). While neither of these variables strictly qualify as indices of convergent or discriminant validity, support for the applicability of the TRIM scales with victims and offenders will be most persuasive when a meaningful correlational pattern is replicated in all groups. As noted in the introduction section, we expect that unforgiving motivations (i.e. high Revenge and Avoidance, and low Benevolence) relate negatively with Accomplished Forgiveness and with Social Desirability response bias, whereas positive associations with Accomplished Revenge, Dispositional Anger and Dispositional Vengeance are expected (e.g., McCullough et al., 2006).

The correlational pattern, summarized in Table 4, corroborated McCullough et al.'s (1998, 2006) conceptualization of Forgiveness as reflecting low Revenge and Avoidance, and high Benevolence motivation: in all subgroups, the correlations between Accomplished Forgiveness and TRIM-scales were all in the expected direction, statistically significant and with, on average, moderate effects sizes $(|.28|<r<|.67|$, $p<.001)$.

Revenge motivation showed moderate to strong positive associations with Accomplished Revenge in all groups (correlations from $r=.33$ to $r=.58, p<.001$ ), and slightly smaller and negative associations with Accomplished Forgiveness (from $r=-.32$ to $r=-.38, p<.001$ ). Revenge motivation was most strongly associated, in all groups, with Dispositional Vengeance (correlations from $r=.49$ to $r=.67, p<.001$ ) and Dispositional Anger (with correlations from $r=.27$ to $r=.79, p<.001$ ). Revenge motivation was not significantly associated with Social Desirability response bias, except in the female students $(r=-.24, p<.001)$.

Avoidant motivation only showed significant and moderate associations with Accomplished Forgiveness (correlations from $r=-34$ to $r=-.48, p<.001$ ), suggesting that people who have forgiven the perpetrator are less motivated to avoid him or her. Avoidance appeared unrelated to Dispositional Anger and Vengeance, Accomplished Revenge, and Social Desirability.

Benevolent motivation was, in all groups, negatively associated with Accomplished Revenge (with correlations from $r=-.24$ to $r=-.29, p<.001)$ and with Dispositional Vengeance (with correlations from $r=-.36$ to $r=-.63$, $p<.001)$, whereas we found positive associations with Accomplished Forgiveness (with correlations from $r=.28$ to $r=.67, p<.001)$. Benevolence was not significantly associated with Dispositional Anger, except in the case of the detainees $(r=-.63, p<.001)$. Benevolence was not related to a Social Desirability response bias in any group $(r<.19$, $p>.05)$.

\section{Differences in TRIM-Scores Between Adolescents and (ex)Detainees}

Table 5 summarizes the means and standard deviations of the TRIM-scores in the various groups of participants (adolescents, men, women, ex-detainees). In a multivariate analysis of covariance, with the three TRIM scales as dependent variables, group (students versus (ex)detainees) as between subjects factor, and with the covariates gender, whether or not physical and sexual violence was reported, we found no multivariate difference between the two groups $(F(3,309)=2.44$, $p=.065)$, indicating that (ex)detainees and adolescents from the general community did not significantly differ in Revenge, 
Avoidance, and Benevolent motivation when gender and offense type was controlled. All covariate effects were, however, significant $(F(3,309)=7.06, p<.001$ for gender; $F(3,309)=2.91, p=.035$ for physical violence; $F(3,309)=$ $6.06, p=.001$ for sexual violence) and indicated more Revenge motivation for men than women $(F(1,311)=9.06$, $p=.003)$, more Revenge $(F(1,311)=3.99, p=.047)$ and less Benevolence $(F(1,311)=8.17 ; p=.005)$ after incidents involving physical violence, and more Avoidance $(F(1,311)=$ $15.72, p<.001)$ after sexual violence.

\section{Discussion}

Victimization by aggression and violence is a prevalent theme in the autobiographies of perpetrators of violence, including convicted offenders (e.g., Jennings et al., 2012; Mulford et al., 2018). Across one's lifetime, the risk of victimization appears highest during adolescence (Cops \& Pleysier, 2014). Victimization during that vulnerable age can instigate a cascade of negative developmental consequences, including the risk of escalating cycles of violent offending and revictimization (e.g., DeCamp et al., 2018; Turner et al., 2015; Stillwell et al., 2008; Widom, 1989). Standardized (and easy) assessment of interpersonal motivation after victimization (e.g., revenge) might then be an aid in risk assessment and threat analysis by signaling potentially (very) aggressive behavior, in forensic settings (Meloy et al., 2012), but also in schools or at the workplace (e.g. Kausch \& Resnick, 2001; Villaruel \& Dunbar, 2006; Wang et al., 2018). In view of its causal role in capital offenses (McCullough et al., 2013), revenge certainly merits close monitoring. Furthermore, and from a victimological point of view, indices of victims' interpersonal motivations toward the perpetrator of their harm might signal possible needs for support, and could inform discussions and decisions in the context of Restorative Justice interventions (Adams, 2016; Choi, Bazemoor \& Gilbert, 2012; Sherman \& Strang, 2010).

In this study, we explored the suitability of a Dutch version of the Transgression Related Interpersonal Motivations scale (TRIM; McCullough et al., 1998, 2006) as a self-report instrument for revenge, avoidance, and benevolence towards the perpetrator in people who are victimized by social transgression, including (criminal) aggression and violence. We translated the TRIM-18 (McCullough et al., 2006; Forster et al., 2019) according to conventional guidelines laid down in the literature on cross-cultural psychology (DeFiguieredo \& Lemkau, 1980) and slightly adapted the instruction. We collected data on this version of the TRIM in adolescents from the general community and detainees who were convicted for violent offences. We expected that this Dutch TRIM would sample a sufficiently broad variety of experiences with victimization. Furthermore, we expected this Dutch TRIM to 
Table 5 Means and SD for TRIM Revenge, Avoidance, and Benevolence scores in three samples of students, male and female students, and (ex)detainees

\begin{tabular}{|c|c|c|c|c|c|c|c|c|c|c|c|c|}
\hline & \multicolumn{2}{|c|}{ Secondary school } & \multicolumn{2}{|c|}{ Secondary vocational school } & \multicolumn{2}{|c|}{ University } & \multicolumn{2}{|c|}{ Male students } & \multicolumn{2}{|c|}{ Female students } & \multicolumn{2}{|c|}{ (Ex)detainees } \\
\hline & mean & $\mathrm{SD}$ & mean & SD & Mean & SD & mean & SD & mean & SD & mean & SD \\
\hline Revenge & 3.20 & 1.40 & 3.57 & 1.47 & 3.12 & 1.30 & 3.50 & 1.53 & 3.07 & 1.36 & 3.00 & 1.74 \\
\hline Avoidance & 4.22 & 1.63 & 3.61 & 1.23 & 3.88 & 1.34 & 3.73 & 1.43 & 4.08 & 1.43 & 4.09 & 1.56 \\
\hline Benevolence & 4.11 & 1.23 & 3.72 & 1.21 & 4.09 & 1.20 & 3.80 & 1.42 & 4.07 & 1.18 & 3.85 & 1.78 \\
\hline
\end{tabular}

have adequate psychometric properties, i.e., an interpretable factor structure that corroborates the a priori scales, with all scales showing sufficient internal consistency and construct validity.

The TRIM was designed to assess interpersonal motivation after a social transgression, i.e., the experience of being hurt by somebody else (McCullough et al., 1998, 2006). It most commonly yields interpersonal responses after relatively mild transgressions. To explore the suitability of the scale as a screening instrument for victimization by aggression and violence, including criminal offenses, we were particularly interested in the extent to which participants might report incidents involving various types of aggression, including both indirect as well as direct aggression, and within the latter category, both physical and sexual violence. Therefore, we slightly altered the TRIM instruction, by explicitly asking respondents for their experiences with injustice or violence (rather than their experience with being hurt by someone close cf. the original TRIM). This yielded responses about a wide variety of victimizing incidents, including penal offences like physical and sexual violence: A substantial proportion (that is, almost 1 in 5) of the adolescents from the general community reported incidents that involved physical and/or sexual violence, whereas $65 \%$ of the (ex)detainees reported such experiences. These relatively high percentages for the adolescents in our study do not deviate grossly from those found in prevalence studies on victimization of adolescents in the Netherlands, which appear to range between $10 \%$ and $30 \%$ (reviewed in Ten Boom \& Wittebrood, 2019), and substantiate the suitability of the TRIM for victims of violence.

It should be noted that about 1 in 6 of our respondents declined to describe and specify the victimizing incident that had hurt them, while they did answer the TRIM items on revenge, avoidance, and benevolence. We can only speculate on the composition of this group in terms of experienced victimization, personal characteristics and circumstances, and how their reluctance to write about the incident might have affected their TRIM responses. Furthermore, as one anonymous reviewer noted, respondents who did describe the victimizing incident may have been primed by the writing, which possibly affected their responses to the TRIM. As a post hoc exploration, we compared the 'Declined to answer' group with the group that did describe the incident, on all variables included in the study, and found only one statistically significant difference, i.e., the 'Declined to answer' group reported on average somewhat less Avoidance motivation $(t(360)=$ 2.75, $p=.006)$. This is hardly illuminating and, if anything, slightly counterintuitive. The question why respondents sometimes refrain from describing a victimizing incident is intriguing, but cannot be answered on the basis of our data; we will need future studies to address this.

Exploratory factor analyses of the 18 TRIM-items yielded three unambiguous and internally consistent components, i.e. revenge, avoidance, and benevolence. This factorial structure corroborated the a priori scales of the original TRIM (McCullough et al., 1998, 2006). It should be noted, however, that both McCullough et al. (2006) and more recently Forster et al. (2019) found a substantial negative association between benevolence and avoidance motivation, with revenge having a more orthogonal contribution to their forgiveness construct. Interestingly, Nouri et al. (2019) reported similar interscale relationships in their Persian version of the TRIM, while we found, in our Dutch version, a relatively small association between benevolence and avoidance (less than $10 \%$ of shared variance) and a moderately strong negative association between benevolence and revenge (25\% of shared variance), suggesting a 'friendly to hostile approach - avoidance' structure underlying our data. While the difference in findings is interesting from a theoretical stance, it should be noted that our study was not designed as a study of the forgiveness construct, nor as a replication trial of the McCullough et al. (2006) and Forster et al. (2019) studies. Future studies, designed with a focus on these issues, are needed to elucidate and replicate findings, and it will be interesting to examine to what extent cross-cultural generalizability can be found.

To investigate the construct validity of the three TRIM scales, associations with social desirability response bias, dispositional vengeance and anger, and accomplished revenge and forgiveness were tested. Revenge motivation was positively and substantially related to respondents' dispositional vengeance and anger, while the association with social desirability response bias appeared negligent. Benevolent motivation showed a similar (but reverse-signed) correlational pattern. Avoidant motivation was not significantly related to dispositional anger and vengeance. A strong negative association was, however, found with accomplished forgiveness: In line 
with theoretical conceptualizations (McCullough et al., 1998; McCullough, 2008; Barnes et al., 2009), respondents who claimed to have forgiven the incident, reported less motivation to avoid the perpetrator. All in all, the correlational pattern generally seems to underpin the TRIMs construct validity. Moreover, the pattern was remarkably stable across the various groups of respondents (i.e., across different educational levels, genders, students and (ex)detainees), which certainly bolsters the generalizability of findings and the suitability of the TRIM for the target populations. Nevertheless, as one anonymous reviewer suggested, future studies in relevant populations can help bolster the scale's convergent validity by relating the TRIM scores to analogue self reports, while predictive validity can be underpinned by the TRIM's associations with behavioral measures.

One intriguing finding in the realm of construct validity merits mention, i.e. the rather strong and positive correlation between accomplished revenge and current revenge motivation. It suggests that respondents who claimed to have avenged the harm inflicted on them, still harbored vengeful thoughts and feelings. At first sight this finding seems somewhat counterintuitive, since restoring the balance in power and suffering by means of revenge might be expected to resolve the motivation to avenge yet again (Frijda, 1994). Our finding does, however, corroborate experimental studies that have shown similarly paradoxical consequences of revenge, i.e. that avengers appear to continue to ruminate about the original perpetrator, while people who do not avenge but 'move on' tend to think less about the offender and the offense (Carlsmith et al., 2008).

There were a few remarkable differences between the various groups of respondents in this study. Firstly, the (ex)detainees reported more incidents involving physical and/or sexual violence than the various student samples did. Statistically controlling for this difference in incident registration, their mean scores for revenge, avoidance, and benevolence motivation did not differ significantly from the student participants. Secondly, the men appeared to report more revenge and less benevolence than the women, in line with meta-analytic findings (Miller, Worthington \& McDaniel, 2008; Fehr et al., 2010). Finally, as was investigated with a finer grained approach in Gerlsma and Lugtmeyer (2018), different offense types appeared to elicit differences in revenge, avoidance, and benevolence. In particular, physical violence seemed to elicit higher revenge scores than other types of incidents, whereas sexual violence elicited more avoidance.

Several methodological limitations should be taken into account in the interpretation of this study's findings. For one thing, the data relies on self-report: We cannot be sure that the reported incidents actually did happen, and that they merit the descriptions provided. However true or biased, these reports are part of participants' narratives about their experiences with victimization and, as such, should be a subject if not the prime focus of investigation (e.g., Pemberton, Aarten \& Mulder, 2019). Furthermore, the sample consisted of a rather imbalanced set of subgroups. The data for the adolescents of the general community was collected in students only, albeit from various educational levels, while working adolescents were not included. Findings may fail to generalize here and we would recommend additional data from a more representative sample of the general population to further bolster the suitability of the TRIM. The same limitation and recommendation should be noted, a fortiori, with regard to the forensic group. The two samples of (ex) detainees together yielded a fairly heterogeneous group. Together with the possibly confounding influence of psychiatric problems and the smallish sample size, this may compromise replicability and generalizability. On the other hand, the robustness of the pattern, the effect sizes and significance levels may somewhat shore confidence in our findings.

Notwithstanding the limitations and need for more data mentioned above, this version of the TRIM does seem to be an informative and psychometrically sound instrument that could well be a valuable aid in risk assessment and risk management of known offenders, in threat assessment of as yet unknown offenders, and in efforts to support victims of violence. In particular, this data provides useful information for researchers and practitioners who want to assess targeted revenge, avoidance, and benevolence motivation in Dutch speaking adolescents and adults, as well as for researchers and practitioners across the world who want to assess revenge, avoidance, and benevolence in response to:

- A wide range of interpersonal transgressions, that is, transgressions that involve both direct and indirect forms of aggression;

- The interpersonal transgressions that might be experienced by victims and perpetrators of severe and criminal offenses;

- An interpersonal transgression that a respondent selects from their lifetime experiences instead of their experiences during the past week or month.

In sum, the TRIM appears to be a reliable yardstick to estimate revenge, avoidance, and benevolence in response to all sorts of transgressions, be they social harms or criminal offenses.

Acknowledgments Our special thanks are due to all participants in this study, to Sandra Fielenbach PhD and Karen Sleurink MSc for their help with data collection, and to three anonymous reviewers for their valuable feedback on an earlier version of this paper.

Data Availability The dataset generated and analysed during the current study is available from the corresponding author on reasonable request. 


\section{Compliance with Ethical Standards}

Conflict of Interest On behalf of all authors, the corresponding author states that there is no conflict of interest.

Ethics Approval This study was approved by the Ethics Committee of Psychology (ECP) of the Faculty of Behavioural and Social Sciences of the University of Groningen, The Netherlands (ecp@rug.nl).

Informed Consent Informed consent was obtained from all individual participants included in the study.

Open Access This article is licensed under a Creative Commons Attribution 4.0 International License, which permits use, sharing, adaptation, distribution and reproduction in any medium or format, as long as you give appropriate credit to the original author(s) and the source, provide a link to the Creative Commons licence, and indicate if changes were made. The images or other third party material in this article are included in the article's Creative Commons licence, unless indicated otherwise in a credit line to the material. If material is not included in the article's Creative Commons licence and your intended use is not permitted by statutory regulation or exceeds the permitted use, you will need to obtain permission directly from the copyright holder. To view a copy of this licence, visit http://creativecommons.org/licenses/by/4.0/.

\section{References}

Adams, G. S. (2016). Asymmetries between victims' and transgressors' perspectives following interpersonal transgressions. Social and Personality Psychology Compass, 10, 722-735. https://doi.org/10. 1111/spc3_12291.

Anderson, C. A., \& Bushman, B. J. (2002). Human aggression. Annual Review of Psychology, 53(1), 27-51. https://doi.org/10.1146/ annurev.psych.53.100901.135231.

Barnes, C. D., Brown, R. P., \& Osterman, L. L. (2009). Protection, payback, or both? Emotional and motivational mechanisms underlying avoidance by victims of transgressions. Motivation \& Emotion, 33, 400-411. https://doi.org/10.1007/s11031-009-9142-4

Barnett, G. D. (2011). What is grievance thinking and how can we measure this in sexual offenders? Legal and Criminological Psychology, 16(1), 37-61. https://doi.org/10.1348/135532509X480339.

Barnoux, M. A., \& Gannon, T. A. (2013). A new conceptual framework for revenge firesetting. Psychology, Crime \& Law, 20, 497-513. https://doi.org/10.1080/1068316X.2013.793769.

Baumeister, R. F. (1996). Evil: Inside human cruelty and violence. New York: W H Freeman/Times Books/ Henry Holt \& Co.

Beck, A. T. (1999). Prisoners of hate: The cognitive basis of anger, hostility, and violence. New York: HarperCollins Publishers.

Beck, A. T. (2002). Prisoners of hate. Behaviour Research and Therapy, 40(3), 209-216. https://doi.org/10.1016/S0005-7967(01)00103-6.

Bloom, S. L. (2001). Commentary: Reflections on the desire for revenge. Journal of Emotional Abuse, 2(4), 61-94. https://doi.org/10.1300/ $\mathrm{J} 135 \mathrm{v} 02 \mathrm{n} 0406$.

Briggs, S. R., \& Cheek, J. M. (1986). The role of factor analysis in the development and evaluation of personality scales. Journal of Personality, 54(1), 106-148. https://doi.org/10.1111/j.1467-6494. 1986.tb00391.x.

Bryant, F. B., \& Yarnold, P. R. (1995). Principal-components analysis and exploratory and confirmatory factor analysis. In L. G. Grimm \& P. R. Yarnold (Eds.), Reading and understanding multivariate statistics (pp. 99-136). Washington, DC: American Psychological Association.
Bushman, B. J. (2002). Does venting anger feed or extinguish the flame? Catharsis, rumination, distraction, anger and aggressive responding. Personality and Social Psychology Bulletin, 28(6), 724-731. https:// doi.org/10.1177/0146167202289002.

Bushman, B. J., Baumeister, R. F., \& Phillips, C. M. (2001). Do people aggress to improve their mood? Catharsis beliefs, affect regulation opportunity, and aggressive responding. Journal of Personality and Social Psychology, 81(1), 17-32. https://doi.org/10.1037/00223514.81.1.17.

Card, N. A., Stucky, B. D., Sawalani, G. M., \& Little, T. D. (2008). Direct and indirect aggression during childhood and adolescence: A metaanalytic review of gender differences, intercorrelations, and relations to maladjustment. Child Development, 79(5), 1185-1229. https:// doi.org/10.1111/j.1467-8624.2008.01184.x.

Carlsmith, K. M., Wilson, T. D., \& Gilbert, D. T. (2008). The paradoxical consequences of revenge. Journal of Personality and Social Psychology, 95(6), 1316-1324. https://doi.org/10.1037/a0012165.

Carmody, P., \& Gordon, K. (2011). Offender variables: Unique predictors of benevolence, avoidance, and revenge? Personality and Individual Differences, 50, 1012-1017. https://doi.org/10.1016/j. paid.2010.12.037.

Choi, J., Bazemore, G., \& Gilbert, M. J. (2012). Review of research on victims' experiences in restorative justice: Implications for youth justice. Children and Youth Services Review, 34(1), 35-42. https:// doi.org/10.1016/j.childyouth.2011.08.011.

Church, A. T., \& Burke, P. J. (1994). Exploratory and confirmatory tests of the big five and Tellegen's three- and four-dimensional model. Journal of Personality and Social Psychology, 66(1), 93-114.

Cops, D., \& Pleysier, S. (2014). Usual suspects, ideal victims and vice versa: The relationship between youth offending and victimization and the mediating influence of risky lifestyles. European Journal of Criminology, 11(3), 361-378. https://doi.org/10.1177/ 1477370813500886.

Crowne, D. P., \& Marlowe, D. (1960). A new scale of social desirability independent of psychopathology. Journal of Consulting Psychology, 24(4), 349-354. https://doi.org/10.1037/h0047358.

De Figueiredo, J. M., \& Lemkau, P. V. (1980). Psychiatric interviewing across cultures: Some problems and prospects. Social Psychiatry, $15,117-121$

DeCamp, W., Zaykowski, H., \& Lunn, B. (2018). Victim-offender trajectories: Explaining propensity differences from childhood to adulthood through risk and protective factors. British Journal of Criminology, 58(3), 667-688. https://doi.org/10.1093/bjc/azx052.

Van Denderen, M., De Keijser, J., Gerlsma, C., Huisman, M., \& Boelen, P. A. (2014). Revenge and psychological adjustment after homicidal loss. Aggressive Behavior, 40(6), 504-511. https://doi-org.proxyub.rug.n1/10.1002/ab.21543

Denson, T. F. (2013). The multiple systems model of angry rumination. Personality and Social Psychology Review, 17(2), 103-123.

Dodge, K. A., Bates, J. E., \& Pettit, G. S. (1990). Mechanisms in the cycle of violence. Science, 250, 1678-1683. https://doi.org/10.1126/ science. 2270481.

Dutton, D. G., \& Hart, S. D. (1992). Evidence for long-term, specific effects of childhood abuse and neglect on criminal behavior in men. International Journal of Offender Therapy and Comparative Criminology, 36(2), 129-137. https://doi.org/10.1177/ $0306624 X 9203600205$.

Fehr, R., Gelfand, M. J., \& Nag, M. (2010). The road to forgiveness: A meta-analytic synthesis of its situational and dispositional correlates. Psychological Bulletin, 136, 894-914. https://doi.org/10.1037/ a0019993.

Forster, D. E., Billingsley, J., Russell, V. M., McCauley, T. G., Smith, A., Burnette, J. L., Ohtsubo, Y., Schug, J., Lieberman, D., \& McCullough, M. E. (2019, December 9). Forgiveness takes place on an attitudinal continuum from hostility to friendliness: Toward a closer union of forgiveness theory and measurement. Journal of 
Personality and Social Psychology. Advance online publication. https://doi.org/10.1037/pspi0000227.

Frijda, N. H. (1994). The lex talionis: On vengeance. In S. M. van Goozen, N. E. Van de Poll, \& J. A. Sergeant (Eds.), Emotions: Essays on emotion theory (pp. 263-289). Hillsdale, NJ: Lawrence Erlbaum Associates, Inc..

Gannon, T. A., Ward, T., Beech, A. R., \& Fisher, D. (2007). Aggressive offenders' cognition: Theory, research and practice. New York: Wiley. https://doi.org/10.1002/9780470746295.

Gerlsma, C., \& Lugtmeyer, V. (2018). Offense Type as Determinant of Revenge and Forgiveness after Victimization: Adolescents' Responses to Injustice and Aggression. Journal of School Violence, 17(1), 16-27. DOI: 10.1080/15388220.2016.1193741

Ghaemmaghami, P., Allemand, M., \& Martin, M. (2011). Forgiveness in younger, middle-aged and older adults: Age and gender matters. Journal of Adult Development, 18(4), 192-203. https://doi.org/10. 1007/s10804-011-9127-x.

Jennings, W. G., Piquero, A., \& Reingle, J. M. (2012). On the overlap between victimization and offending: A review of the literature. Aggression and Violent Behavior, 17, 16-26.

Kaiser, H. F. (1974). An index of factorial simplicity. Psychometrica, 39, 31-36.

Karremans, J. C., \& Van Lange, P. A. M. (2004). Back to caring after being hurt: The role of forgiveness. European Journal of Social Psychology, 34(2), 207-227. https://doi.org/10.1002/ejsp.192.

Karsten, J., Akkerman, B. G. J., Hagenauw, L. A., Gerlsma, C., \& Lancel, M. (2019). Patient-rated impulsivity and aggression compared with clinician-rated risk in a forensic psychiatric sample: Predicting inpatient incidents. Criminal Behaviour and Mental Health, 29, 296307. https://doi.org/10.1002/cbm.2131.

Kausch, O., \& Resnick, P. J. (2001). Assessment of employees for workplace violence. Journal of Forensic Psychology Practice, 1(4), 122. https://doi.org/10.1300/J158v01n04_01.

Kunst, M. J. J. (2011). PTSD symptom clusters, feelings of revenge, and perception of perpetrator punishment severity in victims of interpersonal violence. International Journal of Law and Psychiatry, 34, 362-367. https://doi.org/10.1016/j.ijlp.2011.08.003.

Lankford, A., \& Hakim, N. (2011). From columbine to Palestine: A comparative analysis of rampage shooters in the United States and volunteer suicide bombers in the Middle East. Aggression and Violent Behavior, 16(2), 98-107. https://doi.org/10.1016/j.avb. 2010.12.006

Leary, M. R., Kowalski, R. M., Smith, L., \& Phillips, S. (2003). Teasing, rejection, and violence: Case studies of the school shootings. Aggressive Behavior, 29(3), 202-214. https://doi.org/10.1002/ab. 10061.

Lotto, D. (2017). On the origins of terrorism. The Journal of Psychohistory, 45(1), 12-22 Retrieved from http:// search.ebscohost.com.proxy-ub.rug.nl/login.aspx? Direct $=$ true $\& d b=$ psyh $\& A N=2017-29630-002 \&$ site $=$ ehost live \&scope $=$ site.

McCullough, M. E. (2008). Beyond revenge; the evolution of the forgiveness instinct. San Francisco, CA: Jossey-Bass.

McCullough, M. E., Rachal, K., Sandage, S. J., Worthington, E. r., Brown, S., \& Hight, T. L. (1998). Interpersonal forgiving in close relationships: II. Theoretical elaboration and measurement. Journal of Personality and Social Psychology, 75(6), 1586-1603. https:// doi.org/10.1037/0022-3514.75.6.1586.

McCullough, M. E., Root, L. M., \& Cohen, A. D. (2006). Writing about the benefits of an interpersonal transgression facilitates forgiveness. Journal of Consulting and Clinical Psychology, 74(5), 887-897. https://doi.org/10.1037/0022-006X.74.5.887.

McCullough, M. E., Kurzban, R., \& Tabak, B. A. (2013). Putting revenge and forgiveness in an evolutionary context. Behavioral \& Brain Sciences, 36(1), 41-58. https://doi.org/10.1017/ S0140525X12001513
McCullough, M. E., Pedersen, E. J., Tabak, B. A., \& Carter, E. C. (2014). Conciliatory gestures promote forgiveness and reduce anger in humans. PNAS Proceedings of the National Academy of Sciences of the United States of America, 111(30), 11211-11216. https://doi. org/10.1073/pnas.1405072111.

Meloy, J., Hoffmann, J., Guldimann, A., \& James, D. (2012). The role of warning behaviors in threat assessment: An exploration and suggested typology. Behavioral Sciences \& the Law, 30(3), 256-279. https://doi.org/10.1002/bs1.999.

Miller, T. Q., Smith, T. W., Turner, C. W., Guijarro, M. L., \& Hallet, A. J. (1996). Meta-analytic review of research on hostility and physical health. Psychological Bulletin, 119(2), 322-348. https://doi.org/10. 1037/0033-2909.119.2.322.

Miller, A. J., Worthington, E. L., \& McDaniel, M. A. (2008). Gender and forgiveness: A meta-analytic review and research agenda. Journal of Social and Clinical Psychology, 27, 843-876.

Mulford, C. F., Blachman-Demner, D. R., Pitzer, L., Schubert, C. A., Piquero, A. R., \& Mulvey, E. P. (2018). Victim offender overlap: Dual trajectory examination of victimization and offending among young felony offenders over seven years. Victims \& Offenders, 13(1), 1-27. https://doi.org/10.1080/15564886.2016.1196283.

Nederhof, A.J. (1985) Methods of coping with social desirability bias: A review. European Journal of Social Psychology, 15 (3), 263-280

Nouri, F. L., Lotfali, S., Sahranavard, S., Amiri, F., Fatideh, Z. A., \& Fatideh, N. A. (2019). Measuring forgiveness among Iranian adolescents: Evaluation of psychometric properties of Persian version of transgression-related interpersonal motivations inventory. Current Psychology. https://doi.org/10.1007/s12144-019-0135-5.

Nunnally, J. C. (1978). Psychometric theory. 2nd edition. New York: McGraw Hill.

Orth, U., Montada, L., \& Maercker, A. (2006). Feelings of revenge, retaliation motive, and posttraumatic stress reactions in crime victims. Journal of Interpersonal Violence, 21(2), 229-243. https://doi. org $/ 10.1177 / 0886260505282286$.

Pemberton, A., Aarten, P. G. M., \& Mulder, E. (2019). Stories as property: Narrative ownership as a key concept in victims' experiences with criminal justice. Criminology \& Criminal Justice, 19(4), 404 420.

Rapske, D. L., Boon, S. D., Alibhai, A. M., \& Kheong, M. J. (2010). Not forgiven, not forgotten: An investigation of unforgiven interpersonal offenses. Journal of Social and Clinical Psychology, 29(10), 1100 1130 .

Scheff, T. J. (2011). Social-emotional origins of violence: A theory of multiple killing. Aggression and Violent Behavior, 16(6), 453-460. https://doi.org/10.1016/j.avb.2011.03.007.

Schumann, K., \& Ross, M. (2010). The benefits, costs, and paradox of revenge. Social and Personality Psychology Compass, 4(12), 1193 1205. https://doi.org/10.1111/j.1751-9004.2010.00322.x.

Sherman, L. W., \& Strang, H. (2010). Restorative justice as a psychological treatment: Healing victims, reintegrating offenders. In G. J. Towl \& D. A. Crighton (Eds.), Forensic psychology (pp. 398415). Chichester, UK: Wiley-Blackwell.

Spielberger, C.D. (1980). Preliminary manual for the State-Trait Anger Scale (STAS). Unpublished manuscript, University of South Florida, Tampa, USA.

Stillwell, A. M., Baumeister, R. F., \& Del Priore, R. E. (2008). We're all victims here: Toward a psychology of revenge. Basic and Applied Social Psychology, 30(3), 253-263. https://doi.org/10.1080/ 01973530802375094.

Strelan, P., Di Fiore, C., \& Van Prooijen, J.-W. (2017). The empowering effect of punishment on forgiveness. European Journal of Social Psychology, 47, 472-487. https://doi.org/10.1002/ejsp.2254.

Stuckless, N. (1996). The influence of anger, perceived injustice, revenge, and time on the quality of life of survivor-victims. Dissertation, York University, Ontario, Canada. 
Stuckless, N., \& Goranson, R. (1992). The vengeance scale: Development of a measure of attitudes toward revenge. Journal of Social Behavior \& Personality, 7(1), 25-42.

Subkoviak, M. J., Enright, R. D., Wu, C., \& Gassin, E. A. (1995). Measuring interpersonal forgiveness in late adolescence and middle adulthood. Journal of Adolescence, 18(6), 641-655. https://doi.org/ 10.1006/jado.1995.1045.

Tabachnick, B. G., \& Fidell, L. S. (2007). Using multivariate statistics (5th ed.). Boston: Allyn and Bacon.

Ten Boom, A., \& Wittebrood, K. (2019). De prevalentie van huiselijk geweld en kindermishandeling in Nederland. Den Haag, The Netherlands: WODC.

Turner, H. A., Shattuck, A., Hamby, S., \& Finkelhor, D. (2013). Community disorder, victimization exposure, and mental health in a national sample of youth. Journal of Health and Social Behavior, 54(2), 257-274. https://doi.org/10.1177/0022146513479384.

Turner, H. A., Shattuck, A., Finkelhor, D., \& Hamby, S. (2015). Polyvictimization and youth violence exposure across contexts. Journal of Adolescent Health, 58(2), 208-214. https://doi.org/10. 1016/j.jadohealth.2015.09.021.

Van der Ploeg, H. M., Defares, P. B., \& Spielberger, C. D. (1982). Handleiding bij de Zelf-Analyse Vragenlijst ZAV. Lisse, Netherlands: Swets \& Zeitlinger.

Villarruel, F.A. \& Dunbar Jr., C. (2006) Culture, Race, and Zero Tolerance Policy: The Implications. Journal of Forensic
Psychology Practice, 6(2), 53-63. https://doi.org/10.1300/ J158v06n02 04

Wang, Q., Bowling, N. A., Tian, Q., Alarcon, G. M., \& Kwan, H. K. (2018). Workplace harassment intensity and revenge: Mediation and moderation effects. Journal of Business Ethics, 151, 213-234. https://doi.org/10.1007/s10551-016-3243-2.

Widom, C. S. (1989). The cycle of violence. Science, 244(4901), 160 166. https://doi.org/10.1126/science.2704995.

Witvliet, C., Ludwig, T. E., \& Vander Laan, K. L. (2001). Granting forgiveness or harboring grudges: Implications for emotion, physiology, and health. Psychological Science, 12(2), 117-123. https:// doi.org/10.1111/1467-9280.00320.

Worthington, E. L., \& Wade, N. G. (1999). The psychology of unforgiveness and forgiveness and implications for clinical practice. Journal of Social and Clinical Psychology, 18(4), 385-418.

Worthington, E. R., Davis, D. E., Hook, J. N., Miller, A. J., Gartner, A. L., \& Jennings, D. (2011). Promoting forgiveness as a religious or spiritual intervention. In: J.D. Aten, M.R. McMinn \& E.L. Worthington Jr. (Eds.), Spiritually oriented interventions for counseling and psychotherapy (pp. 169-195). Washington, DC: American Psychological Association.

Publisher's Note Springer Nature remains neutral with regard to jurisdictional claims in published maps and institutional affiliations. 